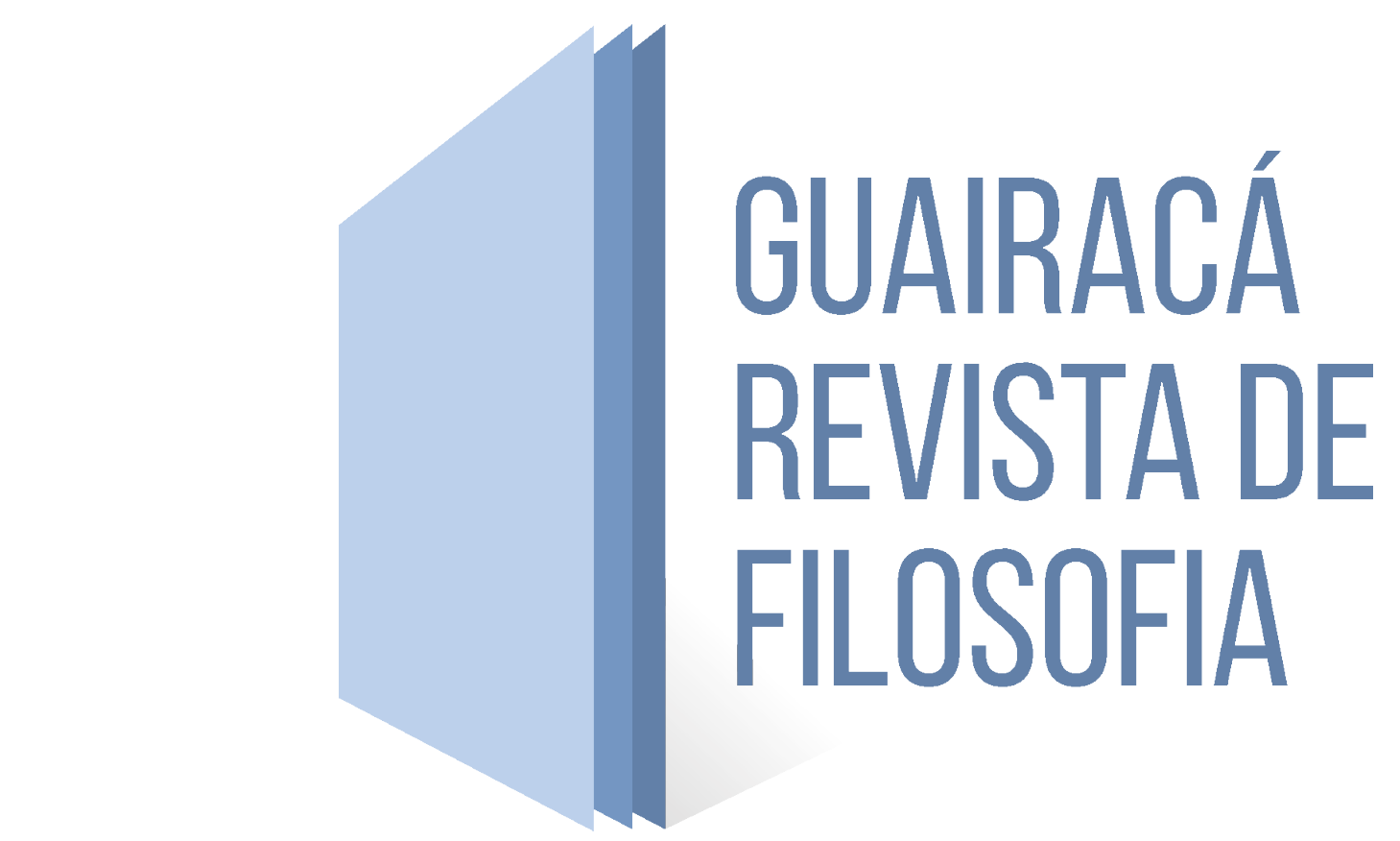

\title{
O ROMANCE COMO EXPEDIENTE HERMENÊUTICO: SOBRE A HISTORICIDADE E A SINGULARIDADE DO EXISTENTE HUMANO
}

Resumo: Trata-se de realizar uma aproximação entre a hermenêutica de Paul Ricoeur (1913 - 2005) e a concepção de arte romanesca de Milan Kundera (1929). Desde perspectivas distintas como a hermenêutica filosófica e a prática da ficção, Ricoeur e Kundera se irmanam na compreensão do entrelaçamento entre a existência na modernidade e a conformação da subjetividade. Desse modo, num primeiro momento caberá realizar a aproximação entre os autores desde a acoplagem do conceito kunderiano de paradoxos terminais dos tempos modernos na hermenêutica da consciência histórica de Ricoeur. No segundo momento, a aproximação se dá entre a concepção de subjetividade do romancista e a hermenêutica do si do filósofo. Intenta-se mostrar como a contribuição de Kundera lança novos desafios a teoria da identidade narrativa de Ricoeur e, com isso, a torna ainda mais interessante e pertinente no debate sobre identidade pessoal.

Palavras-chave: Kundera. Ricoeur. Modernidade. Subjetividade. 


\title{
THE NOVEL AS HERMENEUTIC EXPEDIENT: ABOUT HISTORICITY AND SINGULARITY OF MEN
}

\begin{abstract}
It is an approximation between Paul Ricoeur's (1913 - 2005) hermeneutics and the conception of romanesque art by Milan Kundera (1929-). From different perspectives such as philosophical hermeneutics and the practice of fiction, Ricoeur and Kundera are united in understanding the intertwining between existence in modernity and the conformation of subjectivity. Thus, in the first place, it will be possible to approach the authors since the coupling of the Kunderian concept of terminal paradoxes of modern times in the hermeneutics of Ricoeur's historical consciousness. In the second moment, the approximation takes place between the novelist's conception of subjectivity and the philosopher's hermeneutics of himself. It is intended to show how Kundera's contribution throws new challenges on Ricoeur's theory of narrative identity and thus makes it even more interesting and pertinent in the debate about personal identity.
\end{abstract}

Keywords: Kundera. Ricoeur. Modernity. Subjectivity.

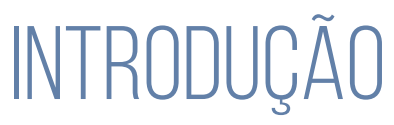

Embora a aproximação entre filosofia e literatura seja eventualmente considerada um ponto pacífico no tocante a sua exequibilidade - como é o caso, por exemplo, da conhecida posição de Ian Watt sobre as irradiações de influência recíproca entre romance e filosofia ${ }^{2}$ - parece sempre pertinente manter em uma distância interrogativa os dois campos dos quais trata o presente artigo. Assim, cabe sempre fazer e refazer a pergunta sobre as possibilidades da interface entre as narrativas de ficção e o pensamento conceitual. No presente trabalho tanto as questões quanto o esboço de resposta para tais questões serão realizados na dupla companhia de um filósofo e de um romancista, a saber, respectivamente, Paul Ricoeur e Milan Kundera. Desse modo, o presente texto tentará elucidar como os romances - e a concepção de romance - de Kundera realizam, em certo sentido, o programa estabelecido por Ricoeur em seus textos de filosofia, especialmente

2. Afirma Ian Watt, em $A$ ascensão do romance: "O paralelo entre a tradição do pensamento realista e as inovações formais dos primeiros romancistas é evidente: filósofos e romancistas dedicaram ao indivíduo particular maior atenção do que este recebera até então. Entretanto a grande atenção que o romance dispensou à particularização da personagem é um tema tão amplo que consideraremos apenas um de seus aspectos mais maleáveis: a maneira pela qual o romancista tipicamente indica sua intenção de apresentar uma personagem como um indivíduo particular nomeando-a da mesma forma que os indivíduos particulares são nomeados na vida real." (WATT, 2010, p. 19) 
no tocante àquilo que o filósofo chama de hermenêutica da consciência histórica e hermenêutica do si. Muito mais do que o mero prazer comparatista, o que o presente texto pretende elucidar é a compatibilidade entre as concepções dos dois autores supracitados e, nesse sentido, o mútuo enriquecimento de ambas as perspectivas. Em um primeiro momento, a hermenêutica da consciência histórica ricoeuriana será aproximada da noção kunderiana de paradoxos terminais desde a qual o romancista faz uma cartografia das experiências e expectativas da modernidade através de um percurso pela história do romance tal como ele a compreende. Na medida em que tanto o o filósofo quanto o romancista percebem um entrelaçamento indissociável entre a constituição das individualidades e o panorama geral da condição humana na modernidade, o segundo momento do artigo visa explorar um novo desafio que surge para a hermenêutica ricoeuriana do si-mesmo quando aproximada do romance de Kundera. Pretende-se que ao final do argumento esteja suficientemente estabelecido que a aproximação dos paradoxos terminais kunderianos e a hermenêutica da consciência histórica realce a estrutura da finitude constitutiva da própria ideia de modernidade. A aproximação das posições dos autores no que concerne ao estatuto da identidade pessoal de um indivíduo, por sua vez, deve elucidar a ampliação do desafio que a planificação das identidades na modernidade é um desafio que coloca novas exigências para a hermenêutica do si de Ricoeur.

\section{A HERMENÊUTICA DA CONSCIÊNCIA HISTÓRICAE OS PARADOXOS TERMINAIS DOS TEMPOS MODERNOS}

É no final de Tempo e narrativa que Ricoeur apresenta explicitamente sua preocupação com a construção de uma hermenêutica da consciência histórica. $\mathrm{Na}$ esteira de uma rejeição do modelo hegeliano de compreensão da História, Ricoeur mobiliza os conceitos de espaço de experiência e horizonte de expectativa tal como são apresentados por Reinhart Koselleck em Futuro passado. Para Ricoeur, enquanto a noção de espaço de experiência "evoca possibilidades de percurso segundo múltiplos itinerários e sobretudo de reunião e de estratificação numa estrutura folheada que faz o passado assim acumulado escapar à simples cronologia", a noção de horizonte de expectativa é vasta o suficiente "para incluir a esperança e o temor, o desejar e o querer, a preocupação, o cálculo racional, a curiosidade, em suma, todas as manifestações privadas ou comuns que visam o futuro" ${ }^{\prime 3}$. As categorias de Koselleck possuem uma pretensão formal e, segundo o próprio autor, enquanto categorias históricas "elas equivalem às de espaço e tempo" ${ }^{4}$ e não podem

3. RICOEUR, 2010, p. 354-355.

4. KOSELLECK, 2006, p. 307. 
ser pensadas uma sem a outra, pois "não há expectativa sem experiência, não há experiência sem expectativa" ${ }^{5}$.

Um elemento que chama atenção nas categorias de Koselleck escolhidas por Ricoeur para orientação de sua hermenêutica da consciência histórica é a de que a própria relação entre expectativa e experiência jazia implícita antes de se colocar em relevo nos tempos modernos. Segundo Ricoeur, só na modernidade "a variação na relação entre horizonte de expectativas e espaço de experiência foi objeto de uma tomada de consciência tão intensa que pôde servir de revelador das categorias sob as quais essa variação pode ser pensada" ${ }^{\prime 6}$. Segundo o próprio Koselleck, "na era moderna a diferença entre experiência e expectativa aumenta progressivamente, ou melhor, só se pode conceber a modernidade como um tempo novo a partir do momento em que as expectativas passam a distanciar-se cada vez mais das experiências feitas até então"7. Ainda segundo este autor, a passagem da hegemonia da historia magistra vitae pré-moderna para a valorização do progresso na modernidade encerrou o paradigma da concepção da História como galeria de exemplos e "a partir de então o horizonte de expectativa passa a incluir um coeficiente de mudança que se desenvolve com o tempo" ${ }^{\prime 8}$.

Se a busca por progresso estendeu a trama da experiência histórica até o ponto de exibir seus extremos constitutivos, porém, no final do século XX já não é possível falar em termos de uma marcha na direção do progresso mas no máximo, segundo Ricoeur, de "aceleração de inúmeras mutações históricas" ${ }^{9}$. Porém, mesmo que Ricoeur admita que uma hermenêutica da consciência histórica deva resistir a tentação das utopias e se dirigir para uma noção sóbria de responsabilidade ${ }^{10}$, seu recurso derradeiro ao pensamento de Nietzsche enquanto expediente de renovação do tipo de relação com a História é indicador da perpétua preocupação do filósofo francês com um âmbito prático e nunca meramente epistemológico das invectivas teóricas e filosóficas. Nesse momento, faço uma incisão no pensamento de Ricoeur e, conforme o gosto do próprio autor, me permito a realização de um enxerto em sua plataforma teórica, a saber, o enxerto de uma contribuição oriunda de uma visão de mundo romanesca.

Concebendo a arte do romance como artefato cultural impensável fora do arco histórico dos tempos modernos, Milan Kundera abre seu $A$ arte do romance com 5. KOSELLECK, 2006, p. 307.

6. RICOEUR, 2010, p. 365.

7. KOSELLECK, 2006, p. 314.

8. KOSELLECK, 2006, p. 317.

9. RICOEUR, 2010, p. 362.

10. Diz Ricoeur: "É preciso resistir à sedução de expectativas puramente utópicas; elas nada mais podem senão desencorajar a ação; pois, por falta de enraizamento na experiência em curso, são incapazes de formular um caminho praticável dirigido para os ideais que elas situam 'em outro lugar'. Expectativas têm de ser determinadas, portanto, finitas e relativamente modestas, para que possam suscitar um engajamento responsável" (RICOEUR, 2010, p. 367). 
um ensaio intitulado $A$ herança depreciada de Cervantes, no qual argumenta que o legado de Cervantes é tão constitutivo da modernidade quanto o de Descartes. Em uma formulação poética, Kundera afirma que

\begin{abstract}
Quando deus deixava lentamente o lugar de onde tinha dirigido o universo e sua ordem de valores, separado o bem do mal e dado um sentido a ccada coisa, Dom Quixote saiu de sua casa e não teve mais condições de reconhecer o mundo. Este, na ausência do Juiz supremo, surgiu subitamente numa temível ambiguidade; a única Verdade divina se decompôs em centenas de verdades relativas que os homens dividiram entre si. Assim, o mundo dos Tempos Modernos nasceu e, com ele, o romance, sua imagem e modelo. (KUNDERA, 1988, p. 12)
\end{abstract}

Para Kundera, tudo se passa como se Descartes fosse o avatar do desejo humano de certezas absolutas e Cervantes o profeta da impossibilidade dessas certezas. E se a filosofia se renovava depois de quase dois milênios de tradição, um modo expressivo e discursivo absolutamente novo surgia vocacionado para a missão ontológica que, segundo Kundera, não poderia ser levada a cabo por nenhuma outra forma discursiva:

\begin{abstract}
A prosa não é apenas uma forma de discurso distinta do verso, mas também uma face da realidade, sua face cotidiana, concreta, momentânea e localizada no lado oposto do mito. (...) Se o romance é uma arte e não apenas um 'gênero literário' é porque a descoberta da prosa é sua missão ontológica, que nenhuma outra arte pode assumir plenamente. (KUNDERA, 2009, p.145)
\end{abstract}

A oncepção de romance de Kundera, portanto, vincula a subjetividade moderna e o modo da prosa propriamente romanesco. Segundo Michel Dion há em Kundera um entrelaçamento indissociável entre a natureza do eu, a mudança histórica e a própria temporalidade, um entrelaçamento que deve ser levado em consideração sob pena de completa incompreensão das obras do romancista tcheco ${ }^{12}$. No escopo da presente contribuição, cabe então averiguar como Kundera compreende a mudança histórica da qual o romance é o observatório privilegiado e,

11. [La prosa no es tan sólo una forma de discurso distinta del verso, sino también una cara de la realidad, su cara cotidiana, concreta, momentánea, y situada em el lado opuesto del mito. (...) Si la novela es un arte y no sólo um 'géreno literario' es porque el descubrimiento de la prosa es su misión ontológica, que ningún outro arte puede asumir enteramente. (KUNDERA, 2009, p. 145)]

12. “Não podemos entender a essência do self sem considerar a natureza do tempo e da mudança histórica. Não podemos apreender a natureza do tempo sem olhar para a essência do eu e da mudança histórica. Não podemos refletir a essência da mudança histórica sem considerar a natureza do eu e a do tempo. Nos romances de Kundera, esses três conceitos filosóficos estão interligados." [“We cannot understand the essence of the self without considering the nature of Time and historical change. We cannot grasp the nature of Time without looking at the essence of the self and of historical change. We cannot reflect the essence of historical change without considering the nature of self and of Time. In Kundera's novels, those three pholosophical conceps are interconnected."] (DION, 2009, p. 78) 
nesse sentido, um poderoso expediente hermenêutico. E é em $A$ arte do romance que Kundera apresenta sua noção de paradoxos terminais:

\begin{abstract}
Os últimos tempos pacíficos em que o homem só tivera a combater os monstros de sua alma, os tempos de Joyce e de Proust, passaram. Nos romances de Kafka, de Hasek, de Musil, de Broch, o monstro vem do exterior e o chamam História; ela não se parece mais com o trem dos aventureiros: ela é impessoal, ingovernável, incalculável, incompreensível - e ninguém lhe escapa. É o momento (o dia seguinte da guerra de 14 em que a plêiade de grandes romancistas centro-europeus percebeu, tocou, apreendeu os paradoxos terminais dos Tempos Modernos. (...) Esses romancistas descobrem 'o que somente um romance pode descobrir': mostram como, nas condições dos 'paradoxos terminais', todas as categorias existenciais mudam subitamente de sentido: que é a aventura, se a liberdade de ação de um K. é totalmente ilusória? Que é o futuro se os intelectuais de $O$ homem sem qualidades não têm a menor suspeita sobre a guerra que, amanhã, irá varrer suas vidas? Que é o crime se Huguenau de Broch não só não se arrepende como se esquece do assassinato que cometeu? E, se o único grande romance cômico dessa época, o de Hasek, tem por cenário a guerra, que aconteceu então com o cômico? Onde está a diferença entre o privado e o público se K., mesmo em seu leito de amor, não fica jamais sem dos agentes do castelo? E que é, neste caso, a solidão? Um fardo, uma angústia, uma maldição, como quiseram que acreditássemos, ou, ao contrário, o valor mais preciso, a ponto de ser esmagado pela coletividade onipresente?" (KUNDERA, 1988, p. 1617)
\end{abstract}

Descoberta por uma plêiade de romancistas que fez "entrar no palco do romance uma inteligência soberana e radiosa" que não transforma o romance em filosofia mas, pelo contrário, faz do próprio romance "a suprema síntese intelectual"13, a realidade dos paradoxos terminais parece o próprio espírito dos tempos modernos em sua fase final. É o que se vê em $A$ imortalidade, por exemplo, quando Kundera propõe que o tempo das grandes ideologias tipicamente moderno já tenha encontrado seu fim, sendo substituído pela época da imagologia. Segundo Kundera, enquanto as ideologas guerreavam, envolviam os povos e as épocas, " $a$ imagologia organiza por si mesma a alterância pacífica de seus sistemas no ritmo alegre das estações"14. Mas o que torna o império da imagologia significativo é que se as ideologias pertencem e caracterizam a História, "o reino da imagologia começa ali, onde a História termina"15. Segundo Trevor Merrill, os romances de Kundera exploram um espaço de epílogo dos tempos modernos sem sair daquilo que Ricoeur considera em termos de uma dialética entre tradição e inovação:

Os romances de Kundera exibem uma consciência fina de seu estatuto de romances, e, além disso, de romances que surgem no momento em que a história do romance aproxima-se do fim. Assim como ele vê Schoenberg como um epílogo fascinante da história da música ocidental, Kundera pode ser situado naquilo que ele chama do

13. KUNDERA, 1988, p. 20.

14. KUNDERA, 1998, p. 117.

15. KUNDERA, 1998, p. 118. 
período "hora extra" do romance, o período dos "paradoxos terminais", em que a cultura ocidental realiza sua própria súmula. Seus romances seguem os caminhos deixados por explorar ao longo da história do gênero e os juntam numa grande síntese, um "arquirromance", para usar o termo que ele aplica a Malaparte em $A$ Cortina.

Ignorar essa novidade em relação ao romance oitocentista seria diminuir a contribuição da obra de Kundera. Seus romances oferecem explorações temáticas inovadoras ("kistch"; "merda"; o amor como algo não sério, "risível") e uma invenção formal sem precedentes (inserir o ensaio no romance ao mesmo tempo que aperfeiçoa a arte da polifonia narrativa foi uma realização importante, certamente uma das mais ricas inovações literárias do século XX). Porém, não há necessidade de exagerar essa especificidade além dos limites. Ainda que resista ao imperativo da story, os romances de Kundera ainda contam histórias; ainda que evite a psicologização, seus personagens ainda tem motivações e traços individuais. Reconhecemos suas inovações como inovações porque elas surgem dentro de uma tradição. (MERRILL, 2016, p. 238)

A tradição, longe de ser concebida como um cemitério de formas, gêneros e tipos, é compreendida por Ricoeur como "uma inovação sempre suscetível de ser reativada por um retorno aos momentos mais criativos do fazer poético"16. Essa inovação, por sua vez, ao operar sobre a superfície sedimentada de uma tradição, aponta para uma relação de crescente tensão entre esses dois polos da tradicionalidade: quanto mais camadas de inovação se sedimentam produzindo uma tradição, mais se alarga o arco no qual a tradição se constitui. Parece ser possível, acompanhando Ricoeur, afirmar sem exageros que não é por acaso que o romance contemporâneo, vinculado a herança de um Miguel de Cervantes localizada na aurora da modernidade, tenha alargado tanto o arco entre a tradição e a inovação que ele "admita ser definido, em grande parte, como antirromance"17.

A inovação, porém, pode não ficar restrita ao interior dos gêneros mas, justamente, ser inovação relativamente aos gêneros. É justamente no que diz respeito as dinâmicas entre a inovação e a tradição sedimentada de inovações passadas que surge uma das mais interessantes preocupações de Paul Ricoeur: a possibilidade da morte da própria prática da narração. Preocupação, aliás, justificada desde a lógica própria interna a seu raciocínio: não há um limite para o alargamento do arco que se estabelece entre os pólos da tradição e da inovação? Não há um ponto onde essa tensão encontraria seu momento terminal e o arco se romperia, cedendo seu espaço a algo tão novo - isto é, tão distinto da prática da narração - que não saberíamos nem mesmo conceber ou imaginar? Afinal, se dentro do arco da prática da narração é possível estabelecer um cortejo de tradições conspícuas justamente por suas presenças discretas mas permanentemente recuperáveis por um olhar hermenêutico, não será o caso de que a própria prática da narração - que certamente teve um começo - não apenas tenha um fim, mas esteja próxima dele? Para Kundera, 16. RICOEUR, 2010a, p. 119.

17. RICOEUR, 2010a, p. 121. 
o destino da arte do romance e o destino dos tempos modernos estão imbricados de forma indissociável e o temor deve ser maior no tocante a ameaças externas ao campo literário do que as possibilidades internas da configuração das narrativas de ficção:

\begin{abstract}
Se Cervantes é o fundador dos Tempos Modernos, o fim de sua herança deveria significar mais que uma simples etapa na história das formas literárias; ela anunciaria o fim dos Tempos Modernos. É por isso que me parece frívolo o sorriso beatífico com que pronunciam necrológios do romance. Frívolo, porque já vi e já vivi a morte do romance, sua morte violenta (através de proibições, censura, pressão ideológica), no mundo onde passei grande parte de minha vida e que habitualmente chamam de totalitário. Então, manifestou-se com toda clareza que o romance era perecível; tão perecível quanto o Ocidente dos Tempos Modernos. Enquanto modelo deste mundo, baseado na relatividade e na ambiguidade das coisas humanas, o romance é incompatível com o universo totalitário. Esta incompatibilidade é mais profunda que aquela que separa um dissidente de um apparatchik, um combatente pelos direitos do homem de um torturador, porque ela é não somente política ou moral, mas ontológica. Isto significa: o mundo baseado numa só Verdade e o mundo ambíguo e relativo do romance são moldados, cada um, de uma matéria totalmente diversa. A Verdade totalitária exclui a relatividade, a dúvida, a interrogação e ela jamais pode portanto se conciliar com o que eu chamaria de espírito do romance. (KUNDERA, 1988, p. 18)
\end{abstract}

O romance de Kundera pode ser pensado na esteira das metamorfoses da intriga concebidas por Ricoeur? Kundera não tem pudor em admitir que a história do romance revela momentos de ocaso de certas figuras da composição e afirma sentir nostalgia da época de Proust, no qual a densidade de uma individualidade ocupava a proa das preocupações e da imaginação dos romancistas ${ }^{18}$. Para Kundera, a figura romanesca constituída pelas eminentes obras de Proust e Joyce encontrou seu ocaso. O autor afirma que na tradição posterior - esta, sim, aberta pela orientação de Kafka - não vigora "nenhum espanto diante do infinito insondável da alma. Antes, um espanto diante da incerteza do eu e de sua identidade"19. A tradição romanesca, portanto, conhece o fim de certas formas do romance desde as razões internas das metamorfoses da intriga e esses finais parciais constituem a própria tradição romanesca. E se Ricoeur encontra nas categorias de Koselleck um instrumental que permite dar conta da tensão interna da temporalidade e da historicidade propriamente modernas, para Kundera são romancistas como Kafka, Musil e Broch que revelam não apenas essa tensão como, em certo sentido, são os narradores dos mal-estares terminais da própria modernidade. O tempo da aventura individual aberto por Cervantes, encolhido pela onipresença da História em Balzac e asfixiado na interiorização da aventura em Flaubert já aparece completamente 18. "A mudança de situação depois de Proust me enche sobretudo de nostalgia. Com Proust, uma imensa beleza se distanca lentamente de nós. E para sempre sem volta." (KUNDERA, 1988, p. 31) 19. KUNDERA, 1988, p. 31. 
devastado nos romances dos autores da plêiade pessoal de Kundera na medida em que, segundo o autor, revelam a asfixia da impossibilidade da aventura humana.

Aproximar os paradoxos terminais kunderianos da hermenêutica da consciência histórica de Ricoeur produz um panorama nada menos do que agônico no qual é preciso assumir uma perspectiva na qual a existência humana, em suas configurações cada vez mais impossíveis em uma modernidade cada vez mais asfixiante, é qualquer coisa como uma tarefa de Sísifo, um jogo que não se pode vencer, uma derrota inevitável ${ }^{20}$. E se o desvio da hermenêutica da consciẽncia histórica pelos paradoxos terminais de Kundera não se dá sem consequências, vejamos brevemente essas consequências no tocante ao domínio das existências singulares tal como concebidas por estes dois autores.

\title{
A HERMENÊUTICA DO SI EODESAFIO DE KUNDERA
}

Nascida como um "rebento frágil proveniente da união da história e da fiç̧ão" 21 a noção de identidade narrativa aparece nas páginas finais de Tempo $e$ narrativa e ganha destaque e protagonismo na reflexão de $O$ si-mesmo como outro. Pensada como uma alternativa tanto ao substancialismo cartesiano quanto ao fluxo descontínuo que caracteriza as noções de identidade pessoal de Hume e Nietzsche, a identidade narrativa encara o desafio, intrínseco as existências humanas, de buscar unidade na temporalidade. Ricoeur admite que "a identidade narrativa não é uma identidade estável e sem falhas" e que "não cessa de se fazer e de se desfazer" 22 . Porém, sem o recurso ao domínio da narratividade, segundo Ricoeur, não é simplesmente possível singularizar uma pessoa. Diz o filósofo:

\begin{abstract}
Segundo a linha de concordância, a personagem haure singularidade da unidade de sua vida considerada como a totalidade temporal, também singular, que a distingue de qualquer outra. Segundo a linha de discordância, essa totalidade temporal é ameaçada pelo efeito de ruptura dos acontecimentos imprevisíveis que a pontuam (encontros, acidentes etc.); a síntese concordante-discordante faz que a contigência do acontecimento contribua para a necessidade de algum modo retroativa da história de uma vida, à qual se iguala a identidade da personagem. Assim, o acaso é transmudado em destino. (RICOEUR, 2014, p. 154, grifos meus)
\end{abstract}

20. É o que afirma o romancista em $A$ cortina: “Os personagens romanescos não pedem para ser admirados por suas virtudes. Querem que os compreendamos, é uma coisa totalmente diferente. Os heróis de epopeia vencem ou, se são vencidos, conservam a grandeza até o último suspiro. Dom Quixote é vencido. E sem nenhuma grandeza, pois imediatamente tudo fica claro: a vida humana como tal é uma derrota. A única coisa que nos resta diante dessa inelutável derrota que chamamos vida é tentar compreendê-la. Eis a razão de ser da arte do romance." (KUNDERA, 2006, p. 17, negrito meu).

21. RICOEUR, 2010c, p. 418.

22. RICOEUR, 2010c, p. 422. 
Em outras palavras: se a narração não esgota a identidade de um indivíduo - se a existência é plenamente ameaçada pela onipresença do acaso que se impõe e exige acomodação -, por outro lado, a ausência da narração parece amputar a existência singular de uma dimensão fundamental de sua constituição ${ }^{23}$. E é nesse atrito entre iniciativas e expectativas pessoais e os assaltos do acaso que o expediente narrativo é convocado para dar unicidade a uma existência ${ }^{24}$.

Assim como a aproximação do conceito de paradoxos terminais tensionou a hermenêutica do si na seção anterior, a aproximação de Kundera da temática da identidade pessoal também intensifica os já hercúleos desafios assumidos pela noção ricoeuriana de identidade narrativa. É sob a rúbrica de ser "uma das mais belas ilusões européias" que Kundera se refere a ideia de "unicidade insubstituível do indivíduo" 25. Em Os caminhos na neblina ${ }^{26}$, oitava parte de Os testamentos traídos, Kundera nos brinda com uma reflexão intitulada Durante quanto tempo pode o homem ser considerado como idêntico a si mesmo ${ }^{27}$. Reconhecendo o mérito de Tolstói em colocar a questão em registro romanesco, o romancista tcheco afirma sobre o russo que este nos oferece uma concepção de que um indivíduo é "um itinerário; uma estrada sinuosa; uma viagem cujas etapas sucessivas não são apenas diferentes, mas muitas vezes representam a negação total das fases anteriores" ${ }^{\prime 28}$. Também afirma que se poderia dizer que as distintas fases de um itinerário "estão em uma relação irônica com as outras" ${ }^{29}$, o que impediria que tais momentos distintos no tempo pudessem ser avaliados em termos de autenticidade ou de moralidade.

23. Um famoso protesto contra essa posição de Ricoeur foi feito pelo filósofo Galen Strawson. Dirigindo sua indignação contra o afã narrativista não só de Ricoeur mas também de autores como Alasdair MacIntyre e Charles Taylor, Strawson sugere que essa imposição da necessidade do recurso a narrativa opera uma verdadeira desumanização daqueles que, ccomo ele próprio, possuem personalidades eposódicas (cf. STRAWSON, 2004).

24. Uma das mais belas celebrações dos assaltos do acaso em existências singulares é feita por Charles Larmore, em As práticas do eu, texto no qual o autor, claramente inspirado em Ricoeur, afirma que "seria possível imaginar que as mudanças e as rupturas de nossa existência se vinculam tão somente à desatenção à inconstância, à falta de seriedade - numa palavra, à inevitável fraqueza humana. E que nossa vida seria dotada de uma 'unidade narrativa' mais substancial, mais coerente e ordenada, integrando-se seus momentos sucessivos num desígnio único, se pudéssemos nos manter à altura das exigências da razão, que nos prescrevem justamente viver nossa vida segundo um plano racional. Acaso não é esse ideal de que importa aproximar-nos o máximo possível, e do qual só nossas fraquezas nos afastam?

Na realidade, não. O imprevisto e as reviravoltas que ele provoca constituem com frequência um bem sem o qual a existência humana seria menos rica, menos apaixonante." (LARMORE, 2008, p. 228-229)

25. KUNDERA, 1988, p. 14.

26. [Los Caminos en la niebla]

27. [Durante cuánto tiempo puede el hombre ser considerado como idéntico a sí mismo?]

28. "un itinerario; un camino sinuoso; un viaje cuyas etapas sucesivas no son sólo distintas, sino que representan con frecuencia la total negación de las fases anteriores" (KUNDERA, 2009, p. 229-230)

29. "se encuentran en una relación irónica las unas com las outras" (KUNDERA, 2009, p. 230). 
Outra asserção sobre os traços estruturais da existência humana podem ser encontrados em digressões reflexivas do romancista nas páginas de $A$ imortalidade. Acentuando o caráter absolutamente casual e contingente do corpo próprio, Kundera afirma que sem um envolvimento apaixonado com a imagem que se vê no espelho seria virtualmente impossível ver singularidade e unicidade mas apenas um exemplar genérico, uma variação do tipo humano em geral:

\begin{abstract}
Uma vez despachados para o mundotal qual somos, primeiro temos quenosidentificar com esse jogo de dados, com esse acidente organizado pelo computador divino: deixar de nos espantarmos precisamente que isso (essa coisa que nos confronta no espelho) seja nosso eu. Se não estivéssemos convencidos de que nosso rosto expressa nosso eu, se não tivéssemos a ilusão primeira e fundamental, não teríamos podido continuar a viver, ou pelo menos levar a vida a sério. E não seria ainda suficiente nos identificarmos com nós mesmos, precisaríamos e uma identificação apaixonada com a vida e com a morte. Pois é graças a essa única condição que não aparecemos a nossos próprios olhos como uma simples variante do protótipo humano, mas como seres dotados de uma essência própria e intransferível. (KUNDERA, 1998, p. 18)
\end{abstract}

A dramaticidade da passagem acima pode ser corroborada por uma brincadeira de Gombrowicz, apresentada em $A$ arte do romance, sobre a densidade de uma identidade como possuindo relação com a quantidade de seres humanos vivos no mundo em determinado momento ${ }^{30}$. A brincadeira de Gombrowicz, lembrada por Kundera no contexto de complementar a ideia do fim da primazia do indivíduo que coincidiu com o fim da hegemonia do estilo proustiano de romance, ajuda a compreender como o romance possui essa prerrogativa de operar como hermenêutica de um tempo histórico. Em $A$ imortalidade Kundera radicaliza a brincadeira de Gombrowicz e encolhe de maneira ainda mais radical a unicidade de um indivíduo ao enfatizar o quanto o repertório de gestos de um indivíduo não é mais do que uma bricolagem de elementos que, estes sim, são muito mais singulares do que os indivíduos humanos. Diz o romancista:

Se nosso planeta viu passar oitenta bilhões de seres humanos, é pouco provável
que cada um deles tenha seu próprio repertório de gestos. Matematicamente, é
impensável. Ninguém duvida que não haja no mundo incomparavelmente menos
gestos do que indivíduos. Isso nos leva a uma conclusão chocante: um gesto é
mais individual do que um indivídio. Para dizer isso em forma de proverbio:
muitas pessoas, poucos gestos. (...) Não podemos considerar um gesto nem como a 30. "Gombrowicz tem uma ideia tão cômica quanto genial. O peso de nosso eu, diz ele, depende da quantidade de população no planeta. Assim Demócrito representava um/quatrocentos milionésimos da humanidade, Brahms um bilionésimo; o próprio Gombrowicz um/dois bilionésimos. Do ponto de vista dessa aritmética, o peso do infinito proustiano, o peso de um eu, da vida interior de um eu, torna-se cada vez mais leve. E, nessa trajetória em direção à leveza, nós atravessamos um limite fatal." (KUNDERA, 1988, p. 31). Outra fonte para essa ideia de Kundera pode ser encontrada n'O homem sem qualidades, de Robert Musil, onde se le em tom quase jocoso que "se dissecássemos a natureza de mil pessoas, haveríamos de encontrar duas dúzias de qualidades, sentimentos, estruturas e assim por diante, que constituem todas essas pessoas" (MUSIL, 1989, p. 49) 
propriedade de um indivíduo, nem como sua criação (ninguém tendo condições de criar um gesto próprio, inteuralmente original e pertencente só a si), nem mesmo como seu instrumento; o contrário é verdadeiro: são os gestos que se servem de nós; somos seus instrumentos, suas marionetes, suas encarnações. (KUNDERA, 1998, p. 13)

O desafio que a perspectiva kunderiana acrescenta àqueles já assumidos pela hermenêutica do si é o da admissão de um baixíssimo coeficiente de unicidade alcançável pelos indivíduos singulares. Talvez seja possível encontrar nas páginas do próprio Ricoeur, porém, um elemento desde o qual o desafio kunderiano não precise ser alocado no rol de detratações da subjetividade pois se uma identidade narrativa tem a forma de uma história, como qualquer história "tem de ser mais que uma enumeração de acontecimentos numa ordem serial, tem de organizá-los numa totalidade inteligível, de modo tal que se possa sempre perguntar qual é o 'tema' da história" ${ }^{31}$. A possibilidade de tipificar histórias a partir de seus temas não implica na possibilidade de tipificar indivíduos a partir dos temas existenciais de suas histórias pessoais ${ }^{32}$ ?

A ideia de tema de uma existência aparece nas páginas de Kundera no segundo capítulo da sexta parte de $A$ imortalidade. Para preparar suas ideias sobre o tema de uma existência, Kundera opera uma longa digressão sobre o poder metafórico da astrologia. O relógio zodiacal seria uma escola de fatalismo, um indicador permanente de uma verdade incontornável: a existência enfrenta o poder da repetição assim como um ponteiro passa várias vezes pelo mesmo lugar. O fato de que os mesmos temas surjam em modos, combinações e intensidades diferentes se explicariam pelo fato de que o relógio zodiacal tem inúmeros ponteiros que se movimentam em diferentes velocidades. Porém, o ensinamento é incontornável: a ideia de que é possível criar de forma livre e espontânea uma nova existência - e, com isso, iniciar uma história nova diferente daquela em que se viveu - é violentamente negada pela metáfora astrológica. É no bojo dessa digressão que Kundera oferece mais uma decisiva contribuição para a ideia de a existência tem a forma de uma história:

31. RICOEUR, 2010a, 114.

32. A possibilidade de sintentizar uma história a partir de seu tema é, para Ricoeur, indicador de certa similaridade entre a estrutura da composição narrativa e o esquematismo de tipo kantiano. Diz Ricoeur: "A imaginação produtiva não só não é destituída de regra, como constitui a matiz geradora das regras. Na primeira Crítica, as categorias do entendimento são inicialmente esquematizadas pela imaginação produtiva. O esquematismo tem essa capacidade, porque a imaginação produtiva tem fundamentalmente uma função sintética. Ela liga entendimento e intuição, gerando sínteses a um só tempo intelectuais e intuitivas. Também a composição da intriga gera uma inteligibilidade mista entre o que já denominamos a chave de ouro, o tema, o "pensamento" da história narrada e a apresentação intuitiva das circunstâncias, dos caracteres, dos episódios e das mudanças de fortuna que constituem o desenlace. É por isso que se pode falar de um esquematismo da função narrativa. (RICOEUR, 2010a, p. 119, negrito meu) 
A vida é assim: não se parece com o romance picaresco onde o herói, de capítulo em capítulo, é surpreendido por acontecimentos sempre novos, sem nenhum denominador comum; é parecida com essa composição que os músicos chamam tema com variações. (...) Você não escapará ao seu destino! (...) Você não escapará ao tema de sua vida! Isso quer dizer que será uma quimera tentar implantar no meio de sua vida uma "vida nova", sem nenhum relacionamento com sua vida precedente, partindo do zero, como se diz. Sua vida será sempre construída com os mesmos materiais, os mesmos tijolos, os mesmos problemas, e o que você poderia considerar no princípio como uma "vida nova" logo aparecerá como uma simples variação do já vivido. (...) Em sua juventude, o homem não está em condições de perceber o tempo como um círculo, mas apenas como um caminho que o conduz direto para horizontes sempre diversos; não percebe ainda que sua vida contém apenas um tema; perceberá isso mais tarde, quando a vida compuser suas primeiras variações. (KUNDERA, 1998, p. 268-269)

Se a ideia de tema de uma vida tal como apresentada por Kundera não só encolhe dramaticamente o estatuto da unicidade e da singularidade alcançáveis por uma via narrativa, por outro lado também encurta o horizonte de expectativas e iniciativas possíveis ao enfatizar que a transformação do acaso em destino se realiza a despeito dos projetos individuais. Depois disso, teria Kundera ainda algum elemento positivo ou consolo de qualquer natureza para oferecer? Aparentemente sim - embora, naturalmente, seja um consolo modestíssimo e muito mais estético do que ético, a saber, a ideia de que a existência humana é perpassada por um desejo de beleza:

Ela [a vida humana] é composta como uma partitura musical. O ser humano, guiado pelo sentido da beleza, transpõe o acontecimento fortuito (uma música de Beethoven, a morte numa estação) para fazer disso um tema que, em seguida, fara parte da partitura de sua vida. Voltará ao tema, repetindo-o, modificando-o, desenvolvendo-o e transpondo-o, como faz um compositor com os temas de sua sonata. (...) O homem inconscientemente compõe sua vida segundo as leis da beleza mesmo nos instantes do mais profundo desespero.

O romance não pode, portanto, ser censurado por seu fascínio pelos encontros misteriosos dos acasos (...) mas podemos, com razão, censurar o homem por ser cego a esses acasos na vida quotidiana, privando assim a vida da sua dimensão de beleza. (KUNDERA, 2008, p. 58, grifos meus)

\section{CONSIDERAÇÕES FINAIS}

A noção kunderiana de paradoxos terminais dá um encaminhamento específico para a hermenêutica da consciência histórica de Ricoeur sem mexer na dinâmica entre inovação e da sedimentação. A modernidade, "como tudo que é humano, contém o germe de seu fim em seu nascimento"33 - e mesmo a ideia

33. KUNDERA, 1988, p. 10. 
de fim da modernidade é, ela própria, um paradoxo terminal ${ }^{34}$. No interior da hermenêutica da consciência histórica de Ricoeur, a ideia de paradoxos terminais tal como apresentada por Kundera revela aquilo que Ricoeur chama de "tristeza do finito"35: se a modernidade já terminou sem que ninguém o perceba e vive o seu epílogo que só seria captável por uma hermenêutica da consciência histórica que resistisse a dissolução da modernidade na qual ela é engendrada - e se, com o fim da modernidade, finda também a arte do romance - tudo se passa como se nos aproximássemos de uma configuração histórica imprevisível e desconhecida. Ao mesmo tempo em que afirma que "não temos a menor ideia do que seria uma cultura em que não se soubesse mais o que significa narrar", Ricoeur também admite que "talvez o romance também esteja morrendo como narração" pois "nada, efetivamente, permite exlcuir que a experiência cumulativa que, pelo menos no campo cultural do Ocidente, ofereceu um estilo histórico identificável, esteja hoje ferida de morte" ${ }^{\prime \prime 36}$. O conceito de paradoxos terminais, portanto, muito mais do que meramente compatível com a hermenêutica da consciência histórica ricoeuriana, a intensifica e a complementa ao enfatizar a possibilidade de que as categorias norteadoras da existência e da história tenham invertido seu sinal e, com isso, entrado em colapso. De modo muito parecido com Koselleck - que reconhece a operatividade das categorias de expectativa e experiência justamente quando elas passam a estabelecer uma relação crítica -, Kundera evidencia mudanças paradigmáticas e entende as fases históricas do romance como monumentos erguidos para as possibilidades e para as expectativas, sejam as realizadas ou as extraviadas. Porém, tudo se passa como se a época de Kafka e Musil - mas que é também de Kundera, de Ricoeur e nossa - testemunhasse o paradoxo terminal da expectativa e da experiência no paradoxo terminal que é a própria ideia de um fim, somente apreensível de forma tardia, da modernidade.

Relativamente ao nível da hermenẽutica do si, a aproximação da concepção kunderiana da individualidade acrescenta tensão ao desafio da identidade hermenêutica ao encolher radicalmente o espaço da unicidade e da singularidade dos indivíduos. Porém, se Kundera apresenta a vida como uma armadilha e o romance como "uma exploração do que é a vida humana, na armadilha em que se transformou o mundo" ${ }^{\prime 37}$, isso não significa que a hermenêutica do si esteja desarmada diante do desafio kunderiano. Muito pelo contrário, é precisamente diante do desafio dos casos desconcertantes de identidade narrativa que a hermenêutica do si realize talvez sua vocação mais íntima, a saber, a de compor a síntese do diverso. Assim

\footnotetext{
34. "A todos os paradoxos terminais, acrescente ainda esse do próprio fim em si mesmo. Quando um fenômeno anuncia, de longe, seu próximo desaparecimento, nós somos muitos a sabê-lo e, eventualmente, a lamentá-lo. Mas quando a agonia chega a seu fim, nós olhamos adiante. A morte se torna invisível. (...) O fim não é uma explosão apocalíptica. Talvez não exista nada tão pacífico quanto o fim." (KUNDERA, 1988, p. 41)

35. RICOEUR, 2010a, p. 52.

36. RICOEUR, 2010b, p. 49.

37. KUNDERA, 1988, p. 222.
} 
como Musil - mestre que Kundera não cessa de elogiar e do qual chega a confessar que é em muitos níveis um imitador ${ }^{38}$ - o romancista tcheco representa um caso desconcertante para a hermenêutica do si. Um caso em que, como diz Ricoeur sobre Musil, "a decomposição da forma narrativa, paralela à perda de identidade da personagem, leva a extrapolar as fronteiras da narrativa e atrai a obra literária para as proximidades do ensaio" ${ }^{\prime 39}$. Kundera oferece um observatório tão privilegiado para a hermenêutica do si que não é exagero dizer que, em certo sentido, a desconcertante prosa digressiva de Kundera realiza a hermenêutica do si. Enriquecida pela ótica kunderiana, a hermenêutica do si deve permanecer significativamente atenta ao tema das narrativas que apreendem existências individuais, apontando para a possibilidade de uma tipificação em termos de gêneros narrativos das possibilidades existenciais $^{40}$.

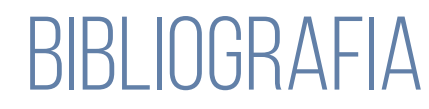

DION, Michel. The dialectics between self, time and historical change according to Milan Kundera. In: TYMIENIECKA, A.-T., (ed.), Analecta Husserliana IC, 77-90. Springer Science+Business Media B.V. 2009.

HEIDEGGER, Martin. Ser y Tiempo. Traducción, prólogo y notas de Jorge Eduardo Rivera. Santiago de Chile: Editorial Universitaria, 1997.

KOSELLECK, Reinhart. Futuro passado: contribuição à semântica dos tempos históricos. Tradução do original alemão Wilma Patrícia Maas e Carlos Almeida Pereira; revisão da tradução César Benjamin. - Rio de Janeiro: Contraponto: Ed. PUC-Rio, 2006.

38. KUNDERA, 1998, p. 53.

39. RICOEUR, 2014, p. 157. Que Musil componha um romance que se confunda com o ensaio por razões relativas ao vínculo estrutural entre identidade pessoal, existência e narração é aceitável e o próprio o confessa indiretamente nas digressões de $O$ homem sem qualidades quando afirma que "um ensaio não é a expressão secundária nem provisória de um conviç̧ão que em melhores condições poderá ser considerada verdade ou reconhecida como erro (só os textos e tratados que os eruditos apresentam como 'dejetos da sua oficina' pertencem a essa espécie); mas um ensaio é a forma única, e irrevogável, que a vida interior de uma pessoa assume num pensamento decisivo." (MUSIL, 1989, p. 183)

40. Minha inspiração aqui é uma afirmação de Heidegger, no final do $\$ 60$ de Ser e tempo e em uma subsequente nota de rodapé nas quais o autor declara que não realizará, no contexto da referida obra, um mapeamento exaustivo das possibilidades fáticas existenciárias disponíveis aos existentes humanos - mapeamento que presumiria, por sua vez, a realização de uma antropologia existencial temática. Heidegger também afirma que a Psicologia das visões de mundo, de Karl Jaspers, pode ser vista como um esboço dessa tarefa na medida em que investiga o ser humano a partir de suas possibilidades. Heidegger afirma ainda que a obra de Jaspers é melhor compreendida se for vista dessa forma do que se for pensada enquanto uma mera lista de tipos de visões de mundo (cf. HEIDEGGER, 1997, p. 294). 
KUNDERA, Milan. A arte do romance: (ensaio). Tradução de Teresa Bulhões C. da Fonseca e Ver Mourão. - Rio de Janeiro: Nova Fronteira, 1988.

KUNDERA, Milan. A cortina: ensaio em sete partes. Tradução Teresa Bulhões Carvalho da Fonseca. - São Paulo: Companhia das Letras, 2006.

KUNDERA, Milan. A imortalidade. Tradução de Teresa Bulhões Carvalho da Fonseca e Anna Lucia Moojen de Andrada. São Paulo: Círculo do Livro, 1998.

KUNDERA, Milan. A insustentável leveza do ser. Tradução de Teresa Bulhões Carvalho da Fonseca. 1. ed. São Paulo: Companhia das Letras, 2008.

KUNDERA, Milan. Los testamentos traicionados. - $1^{\text {a }}$ ed. $1^{\text {a }}$ reimp. - Buenos Aires: Tusquets Editores, 2009.

LARMORE, Charles. As práticas do eu. Tradução de Maria Estela Gonçalves. São Paulo, SP: Editora Loyola, 2008.

MERRILL, Trevor Cribben. O livro da imitação e do desejo: lendo Milan Kundera com René Girard. Tradução de Pedro Sette-Câmara. - 1. ed. - São Paulo: É Realizações, 2016.

MUSIL, Robert. O homem sem qualidades. Tradução de Lya Luft e Carlos Abbenseth. - Rio de Janeiro: Nova Fronteira, 1989.

RICOEUR, Paul. O si mesmo como outro. Tradução Ivone C. Benedetti. - $1^{\text {a }}$ ed. São Paulo: Editora WMF Martins Fontes, 2014.

RICOEUR, Paul. Tempo e Narrativa. (Tomo I) Tradução de Márcia Valéria Martinez de Aguiar; introdução de Hélio Salles Gentil. - São Paulo: Editora WWF Martins Fontes, 2010.

RICOEUR, Paul. Tempo e Narrativa. (Tomo II) Tradução de Márcia Valéria Martinez de Aguiar; introdução de Hélio Salles Gentil. - São Paulo: Editora WWF Martins Fontes, 2010.

RICOEUR, Paul. Tempo e Narrativa. (Tomo III) Tradução de Márcia Valéria Martinez de Aguiar; introdução de Hélio Salles Gentil. - São Paulo: Editora WWF Martins Fontes, 2010.

STRAWSON, Galen. Against narrativity. Ratio 17 (2004): 428-52.

WATT, Ian. A ascensão do romance: estudos sobre Defoe, Richardson e Fielding. Tradução de Hildegard Feist. - São Paulo: Companhia das Letras, 2010. 